\title{
Marking with a Dye to Visualize the Limits of Resection in Breast Conserving Surgery
}

\author{
Sidy Ka ${ }^{1 *}$, Mamadou M Dieng ${ }^{2}$, Jaafar Thiam ${ }^{1}$, Adja Coumba Diallo ${ }^{1}$, Yaye C Diouf ${ }^{1}$, Yacine Mbacké ${ }^{1}$, Michel Mouelle ${ }^{1}$, Doudou \\ Diouf $^{3}$ and Ahmadou Dem ${ }^{1}$
}

${ }^{1}$ Surgical Oncology Unit, Joliot Curie Cancer center, Dakar, Sénégal
${ }^{2}$ Radiation Therapy Unit, Joliot Curie Cancer center, Dakar, Sénégal
${ }^{3}$ Medical Oncology Unit, Joliot Curie Cancer center, Dakar, Sénégal

*Corresponding author: Sidy Ka, institut Joliot Curie, Dakar, Sénégal; Email: sidy.ka@ucad.edu.sn

Received: January 21, 2021; Accepted: January 29, 2021; Published: February 12, 2021

\begin{abstract}
Objective: To study the technical aspects of the marking of the resection margins with a dye in breast-conserving surgery and to evaluate its aesthetic and oncological impacts.

Methods: Injection of methylene blue on a perpendicular path, at a controlled distance from the tumor. The tumor has previously been located by ultrasound or palpation. Then we study the carcinological and aesthetic results.

Results: Over a period of 4 years we operated on 36 patients. The average age was 43 . Large breasts of average size were found in the majority of cases. Tumor sizes were dominated by T3 tumors and tumors were mostly located in the upper outer quadrant. The most frequently encountered histological types were invasive carcinomas with non specific type. The incisions were classic in more than $80 \%$ of cases or sometimes oncoplastic. The aesthetic results were satisfactory in $78 \%$ of cases. The carcinological results were marked by invaded margins in $3 \%$ of patients.
\end{abstract}

Conclusion: The results of the methylene blue injection technique to secure the excision margins and perform breast conserving surgery are satisfactory from the aesthetic and oncological point of view.

Keywords: Marking; Methylene blue; Aesthetic results; Oncological results.

\section{Introduction}

Breast cancer surgery is basically a total mastectomy or breastconserving surgery (BCS) which is a partial removal of the gland, removing the tumor and a margin of healthy tissue. This resection is associated with a sentinel lymph node biopsy or an axillary dissection. For non-palpable lesions, identification by medical imaging with the placement of a harpoon helps guide the excision. For lesions of larger sizes, guidance and assessment of the margins is done by ultrasound or palpation of the mass [1]. Extemporaneous examination of lumpectomy specimens shows invasion of the margins and a need for resection in $25 \%$ of cases [2]. In daily practice at the Dakar Cancer Institute, we consider larger margins for BCS and breast cancer oncoplasty. For this we have introduced into our practice the peritumoral injection of methylene blue and oncoplasty techniques for conservation. The objective of this work was to study the technical aspects of dye marking in BCS and to assess its aesthetic and carcinological impacts.

\section{Materials and Methods}

Patients had to present with a tumor smaller than $4 \mathrm{~cm}$ initially or after chemotherapy. Pure methylene blue, a $10 \mathrm{cc}$ syringe and

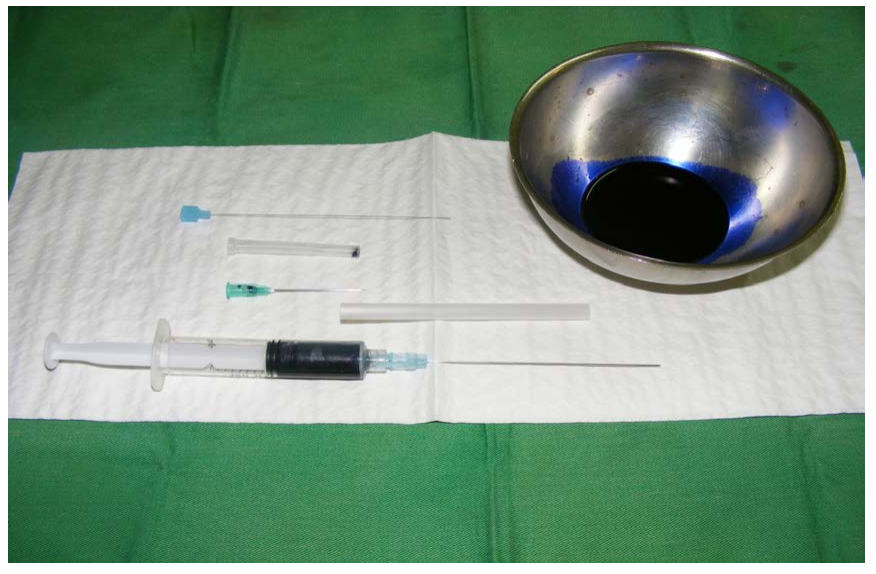

Figure 1: Injection Equipment.

a spinal anesthesia needle were used (Figure 1). The injection was around the tumor and more than $3 \mathrm{~cm}$ from the edges after localization by palpation or ultrasound (Figure 2), from the skin to the pectoralis major apnevrosis. The excision was done on the blue paths (Figure 3). We used Krishna Clough classification to assess aesthetic results. 


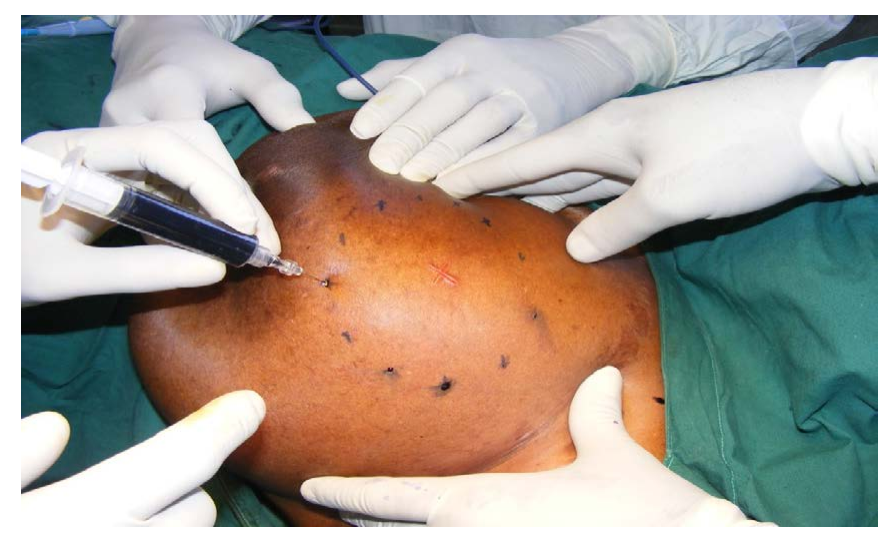

Figure 2: Infiltration of methylene blue over $3 \mathrm{~cm}$.

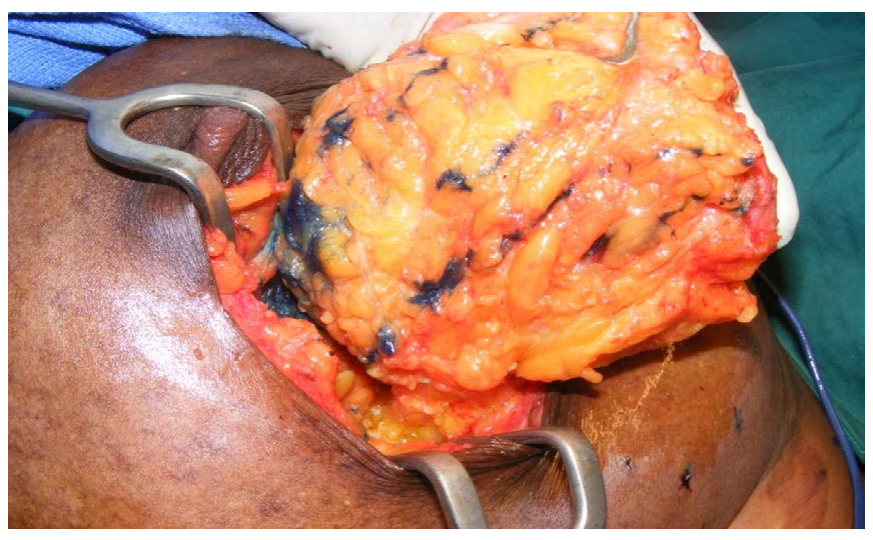

Figure 3: Resection on the blue path.

\section{Results}

Over a period of 4 years we operated on 36 patients. The average age was 43 with extremes of 25 and 62. Large breasts were found in $27 \%$ of cases, medium-sized breasts in $56 \%$ of cases and small breasts in $17 \%$ of cases. At the tumor level, 6 patients (16\%) were classified as T1, 16 patients (44\%) were classified as T2 and 14 patients (40\%) were classified as T3. The tumor was located in 20 patients in the supero-external quadrant, i.e. $56 \%$ of cases. The histologic types were distributed as follows: 27 cases of Invasive Carcinomas with non Specific Type (ICNST) (50\%), 2 cases of In Situ carcinoma (ISC) (12\%), 2 cases of atypical ductal hyperplasia (ADH) (12\%), 1 case of relapsed grade 2 phyllodes tumor (6\%), 1 case of mammary lymphoma (6\%), 1 case of ADH and ISC association (6\%), 1 case of ICNST and ISC association (6\%), 1 case of ICNST and lobular larcinoma association $(6 \%)$ ). The predominant incision was the orange quarter (14 patients or $39 \%$ of cases). The other types of incision were periareolar (8 patients, $22 \%$ of cases), triangular ( 2 patients, $0.03 \%$ of cases), "batwing" and "hemibatwing" types (10 patients, $14 \%$ of cases). All patients had clear margins at the macroscopic specimen examination. At microscopic level, margins were invaded in 1 patient, i.e. $3 \%$ of cases, by an ISC of an extensive nature with foci of ADC giving rise to the indication of a mastectomy. One patient, $3 \%$ of cases, presented $1 \mathrm{~mm}$ close margins. Simple monitoring following radiotherapy was decided. The 1-year MRI was normal. We found 28 satisfactory aesthetic results, i.e. $78 \%$ of cases, 6 average results and 2 bad results. Four patients, i.e. 12\% of cases, presented breast lymphatic drainage disorders with chronic pain and in 1 case 1 episode of acute lymphangitis. After 4 years follow up we found 1 recurrence $(2,7 \%)$.

\section{Discussion}

Young women benefit more from BCS than older women [3]. The breast shape of the young woman is a better guarantee of a good breast conserving technique. The injection of methylene blue is all the easier because the breast is less flabby. It is the same with the size of the breasts. The concern for a good margin is less in large breasts. The larger breast size is an argument of choice in BCS [4]. The tumor size and the extensive in situ component, especially in combination with foci of atypical hyperplasia, are risk factors for local recurrence. The size of the tumor is a risk factor for local recurrence and long-distance dissemination. Tumors larger than $5 \mathrm{~cm} \mathrm{~N}+$ have an $84 \% 5$-year survival rate [1]. The tumor site did not change the injection technique. Upper and outer quadrant (UOQ) tumors are more accessible to conventional techniques because the gland is more developed and axillary dissection is done through the same incision. Lumpectomy of the UOQ offers more possibilities for simple surgery without recourse to oncoplastic reconstruction techniques [4]. Local recurrence and invaded margins were correlated with histological type. The presence of a combination of ductal carcinoma and extensive carcinoma in situ as well as large lesion size, presence of nuclear pleomorphism, absence of cellular polarisation and extensive necrosis has been implicated [5]. The surgery of phyllodes tumors owes its success to a good excision passing in clear margins. Lymphoma is a rare tumor of the breast. Its treatment is BCS and treatment of micrometastatic disease. In case of microscopic residue, if margins are not demarcated the risk of recurrence increases. Neo-adjuvant chemotherapy tends to reduce the risk of local recurrence despite the role of advanced nodal involvement at diagnosis, residual tumor larger than $2 \mathrm{~cm}$, multifocal residual disease, and lymphovascular space invasion [6]. The type of incision depends on the tumor location, the breast and the tumor size, and the breast shape. The decisionmaking factors on the type of incision are the proximity of the tumor to the skin, the tumor site, the size of the breast, the possible conversion to mastectomy after a definitive histological result, with the possibility of immediate reconstruction, the choice expressed by the patient or the need to perform breast reduction or symmetrization at the same time. Oncoplastic technics using upper and lower pedicles, inverted T, pure vertical technics or round-block can be used independently of the location. More and more tumor size does not matter in the decision [7]. Symmetrization by glandular or skin excision may be an aesthetic imperative in carefully selected patients [8]. Aesthetic sequelae that occur in 20 to $30 \%$ of cases associate breast deformities, areola malposition and skin damage [4]. The sequelae are aggravated by radiotherapy of the breast. This led to the development of radiotherapy techniques on the site, in particular the Accelerated Partial Breast Irradiation (APBI). This radiotherapy modality, which includes interstitial brachytherapy, intraoperative radiotherapy and hypofractionation, although not very widespread, has been validated as a safe alternative because it gives recurrence rates almost identical to RTE with less chronic sequelae on breast and critical organs including the heart and lungs $[9,10]$. The oncological results are progressive over time. The recurrence and death rate is low. BCS does not increase mortality. The choice of technique must obey technical and carcinological requirements. 


\section{Conclusion}

Identifier les marges dans BCS à l'aide d'un colorant pour cibler le chemin de coupe est une technique simple et bien tolérée. C'est une contribution importante à la sécurisation des marges et à la gestion des grosses tumeurs. Les résultats esthétiques et carcinologiques sont satisfaisants.

\section{References}

1. Kapoor MM, Patel MM, Scoggins ME (2019) The Wire and Beyond: Recent Advances in Breast Imaging Preoperative Needle Localization. Radiographics 39:1886-1906.

2. Rubio IT, Ahmed M, Kovacs T, Marco V (2016) Margins in breast conserving surgery: A practice-changing process. Euro J Surg Oncol 42: 631-640. [crossref]

3. Lazow SP, Riba L, Alapati A, James TA (2019) Comparison of breast-conserving therapy vs mastectomy in women under age 40: National trends and potential survival implications. Breast J 25: 578-584. [crossref]

4. Bertozzi N, Pesce M, Santi PL, Raposio E (2017) Oncoplastic breast surgery: comprehensive review. Eur Rev Med Pharmacol Sci 21: 2572-2585. [crossref]
5. Provenzano E, Hopper JL, Giles GG, Marr G, Venter DJ, et al. (2004) Histological markers that predict clinical recurrence in ductal carcinoma in situ of the breast: an Australian population-based study. Pathology 36: 221-229.

6. Chen AM, Meric-Bernstam F, Hunt KK, Thames HD, Oswald MJ, et al. (2004) Breast conservation after neoadjuvant chemotherapy: the MD Anderson cancer center experience. J Clin Oncol 22: 2303-2312. [crossref]

7. Walcott-Sapp S, Srour MK, Lee M, Luu M, Amersi F, et al. (2020) Can Radiologic Tumor Size Following Neoadjuvant Therapy Reliably Guide Tissue Resection in Breast Conserving Surgery in Patients with Invasive Breast Cancer?. Am Surg 86: 1248-1253. [crossref]

8. Deigni OA, Baumann DP, Adamson KA, Garvey PB, Selber JC, Caudle AS, Smith BD et al. (2020) Immediate Contralateral Mastopexy/Breast Reduction for Symmetry Can Be Performed Safely in Oncoplastic Breast-Conserving Surgery. Plast Reconstr Surg 145: 1134-1142. [crossref]

9. Romero D (2020) APBI is an alternative to WBI. Nat Rev Clin Oncol 17. [crossref]

10. Veronesi U, Cascinelli N, Mariani L, Greco M, Saccozzi R, et al. (2002) Twenty-year follow-up of a randomized study comparing breast-conserving surgery with radical mastectomy for early breast cancer. N Engl J Med 347: 1227-1232. [crossref] 